Editorial

\title{
Chronic inflammation and carcinogenesis
}

Keywords: chronic inflammation, erythrocyte sedimentation rate, serum acute phase reactant, C-reactive protein, malignant neoplasms

\section{Editorial}

As an approved concept, chronic accumulation of leukocytes and inflammatory mediators in background of chronic inflammation, predispose susceptible cell to mal genesis and neoplastic transformation. ${ }^{1,2}$ This condition occurs when the generation of free radicals and active intermediates in an organ exceeds the system's ability to neutralize and eliminate them. ${ }^{3}$ Chronic inflammation could result from a variety of factors including bacterial, viral and/ or parasitic infections, chemical irritants and non-digestible particles. The longer the inflammation persists, the higher the risk of associated carcinogenesis. ${ }^{4,5}$

Several inflammatory mediators such as TNF- $\alpha$, IL-6, TGF- $\beta$, and IL-10 have been shown to participate in both the initiation and progression of cancer. ${ }^{6}$ In this regard, measurement of serum acute phase reactant (APR) levels is useful because their abnormalities generally reflect the presence and intensity of an inflammatory process. However, APR measurements in clinical practice are not specific to any particular disease, nor can they distinguish infection from other causes of acute and/or chronic inflammation. ${ }^{7}$ The most widely used indicators of the acute phase response are the erythrocyte sedimentation rate (ESR) and C-reactive protein (CRP) levels. The causes of elevation of these indicators include systemic and localized inflammatory and infectious diseases, malignant neoplasms, tissue injury/ischemia and trauma. ${ }^{8,9}$ Measurement of APRs may be helpful in assessing the prognosis in some patients with malignancy, assessing the presence or absence of tumor recurrence and distinguishing a clonal growth from a reactive process. ${ }^{10}$ This concept further emphasizes the importance of cause and treating chronic inflammation that is predisposing factor for large number of poor outcome conditions including GI malignancies. ${ }^{11}$

We should highlight the road map for young researchers to put step in the way, which would result in further determination of exact role of each mediator and inflammatory process and human capability to control many poor conditions to achieve a better future as harvest.

\section{Acknowledgments}

None.

\section{Conflicts of interest}

The authors declare there are no conflicts of interest related to the article.

\section{Funding}

None.
Volume 10 Issue 4 - 2019

\author{
Pezhman Alavinejad,' Amin Sabbaghan² \\ 'Departmet of Gastroenterology \& Hepatology, Ahvaz \\ Jundishapur University of Medical Sciences, Iran \\ ${ }^{2} \mathrm{GI}$ Fellowship, Ahvaz Jundishapur University of Medical \\ Sciences, Iran
}

Correspondence: Pezhman Alavinejad, Associate Professor of Gastroenterology \& Hepatology, Ahvaz Jundishapur University of Medical Sciences, Ahvaz, Iran, Tel 9891611 I 5880, Email pezhmanalavinejad@gmail.com

Received: July 12,2019 | Published: July 17, 2019

\section{References}

1. Aggarwal BB, Vijayalekshmi RV, Sung B. Targeting inflammatory pathways for prevention and therapy of cancer: short-term friend, longterm foe. Clin Cancer Res. 2009;15(2):425-430.

2. Alavinejad P, Nayebi M. Inflammation in Gastrointestinal Tract and Its Importance. Acta Scientific Gastrointestinal Disorders. 2019;2(5):1-2.

3. Hanahan D, Weinberg RA. The hallmarks of cancer. Cell. 2000;100(1):5770 .

4. Bartsch H, Nair J. Chronic inflammation and oxidative stress in the genesis and perpetuation of cancer: role of lipid peroxidation, DNA damage, and repair. Langenbecks Arch Surg. 2006;391(5):499-510.

5. Aggarwal BB, Shishodia S, Sandur SK, et al. Inflammation and cancer: how hot is the link? Biochem Pharmacol. 2006;72(11):1605-1621.

6. Landskron G, De la Fuente M, Thuwajit P, et al. Chronic inflammation and cytokines in the tumor microenvironment. J Immunol Res. 2014; 2014:149185.

7. Markanday A. Acute phase reactants in infections: evidence-based review and a guide for clinicians. Open Forum Infect Dis. 2015;2(3):ofv098.

8. Kushner I. Acute phase reactants. UpToDate. 2015.

9. Kisilevsky R, Manley PN. Acute-phase serum amyloid A: perspectives on its physiological and pathological roles. Amyloid. 2012;19(1):5-14.

10. Wu Y, Potempa LA, El Kebir D, et al. C-reactive protein and inflammation: conformational changes affect function. Biol Chem. 2015;396(11):11811197.

11. Perkins DJ, Patel MC, Blanco JC, et al. Epigenetic mechanisms governing innate inflammatory responses. J Interferon Cytokine Res. 2016;36(7):454461 . 